\title{
Rosemary Lee
}

\section{OPERATIVE IMAGE: AUTOMATION AND AUTONOMY}

\begin{abstract}
Visual media is increasingly impacted by algorithmic approaches to image production, which introduce new modalities into existing notions of the image. Rather than a fundamentally new phenomenon, current methodologies instead expand upon the automation of image production described by previous theories regarding the technological character of the image. The "operative image" (Farocki) acts as a central theory to describe attributes of new forms of visual media engaged with algorithmic processes. Introducing and elaborating on the concept of the operative image, comparisons are drawn between existing notions of the image and new features which result from the use of algorithmic processes in the creation of images. This paper aims to develop an understanding of how algorithmic image production affects defining aspects of images.
\end{abstract}

APRJA Volume 8, Issue 1, 2019

ISSN 2245-7755

CC license: 'Attribution-NonCommercial-ShareAlike'. 


\section{Introduction}

The image has undergone a remarkable transformation over the past few decades, in large part due to the increasing role algorithmic processes play in image production. Harun Farocki's notion of the "operative image" has been especially influential in describing attributes of new forms of images which estrange the point of view from the human subject and eschew representation in favour of the performance of machinic operations. This draws upon changes in the nature of images which had already been ongoing for many years before they were highlighted by Farocki in 2001, but which reached critical mass in the military and governmental use of intelligent machines and surveillance technologies in the 1990s. This research invokes the operative image as a fundamental concept to understanding the paradigm shift toward algorithmic approaches to the image. Images are increasingly automated using machines, and more and more often this is done through opaque systems which obscure the process behind the production of the image from human oversight. The automation of visual tasks ultimately raises questions regarding not only how the image is to be defined in light of algorithmic image production but also as to the autonomy of artificial intelligence to produce images. The present investigation begins by introducing the concept of the operative image, which is then elaborated upon through examination of the historical context which has led up to current image production. Following the themes of automation and autonomy, the operative image is then elaborated upon with regard to these two historical tendencies in imaging technologies.

\section{Operative Image}

The operative image is central to understanding algorithmic forms of visual media, as it departs from previous notions of the image which have tended to prioritise the visual attributes of images. Instead, the operative image considers images in terms of the performance of spatial procedures. In Farocki's words, operative images "are images that do not represent an object, but rather are part of an operation." ("Phantom Images" 17) This kind of image is concerned with the performance of an operation, connected to the real by enacting a process, rather than representing something other than itself.

It's worth noting that the idea of the operative image was inspired by Roland Barthes' concept of the "image-at-one's disposal," which he uses to describe the potential for images and words to function in an instrumental (Parisi) capacity: "I 'speak the tree', I do not speak about it. This means that my language is operative, transitively linked to its object; between the tree and myself, there is nothing but my labour, that is to say, an action." (Barthes, Mythologies 146) The operation performed when "speaking the tree," as Barthes refers to it, is at once an act of conjuring, which performs a representational function, by bringing to mind the mental image of a tree by invoking it by name, but words also function as instruments, ways of interacting with reality. The tree, here, is an implement for performing the concept of a tree. The image, tree, conjured in the process of using that word is operative in the sense that it is a performative and functional conceptual image of a tree, which is not fixed. Metaphor allows words to perform with a great degree of variability upon the relations between the sensual properties of objects and the objects themselves (Harman). Language, in this instrumental 
sense, grants different access to interacting with the real tree one encounters, and may transform those encounters conceptually, as well as ontologically (González Valerio).

In his seminal essay "Phantom Images" and associated trio of video works, Eye/ Machine I-III, Farocki introduces the terms "operative image" and "operational image."[1] An operative image, he explains, results from the performance of an operation ("Phantom Images" 6). Performing an operation through or as an image, Barthes notes, makes it into an action, rather than an object or mere representation. The operative image, thus, is not to be thought of as necessarily representative of something else. Rather, it exists for itself, to the degree that it is concerned with the execution of a spatial task, and may not point to something beyond itself. Additionally, the performance of an operative image tends to prioritise the machine as the producer of this kind of image. This takes a radical departure from the representational paradigm, as the outcome of the performance of an operative image may or may not be visible to humans. The point of view, thus, is shifted from the subject's eye, to being situated in a machinic performance of an operation. The ' $l$ ', as well, is displaced from the human subject to the viewpoint of an apparatus.

Farocki describes machines as possessing a "sightless vision" reliant on computational processes, such as the programmed navigation of robots and drones. In his video trilogy, Eye/Machine I-III, viewers are faced with several examples of what he means by operative image. One scene features a robot performing tasks autonomously, cutting between shots of the robot moving around in a room and shots taken from its point of view, highlighting written numbers in colour as if to indicate the robot's reading those as salient features. In similar fashion, video clips from what appears to be a navigational assistance system are overlaid with markings indicating what appears to be the system's assessment of features in its environment. Different coloured, crudely drawn marks on the video designate the edges of the road or various obstructions in the path of the vehicle. And in scenes which Farocki mentions in "Phantom Images," footage taken by drones navigating autonomously in search of targets is alternated with a human operator tasked with watching the footage and overseeing remote missile strikes. The contrast between human and machine vision is highlighted by these examples, which point to the autonomous quality of performing visual processing tasks automatically by computers, robots and drones.

\section{Automation}

While the process-oriented and non-optical aspects of algorithmically-produced images are contemporary issues, this shift is also deeply rooted in historical developments in the automation of image production. Automating aspects of the creation of images through various techniques and machinery has a long history, which has contributed to the context surrounding current forms of image production. In this section, a review of key examples helps to develop a background against which to compare current trends in image production.

Algorithmic procedures have come to be a defining aspect of current visual media, especially due to the amount of visual processing tasks are now commonly delegated to computers. They are encountered frequently, playing a role in the creation of content, in determining what is visible to whom on the web and in governance through masssurveillance. In light of this shift, the nature of the image can no longer be solely understood in terms of previous formulations which 
frame the image as a fixed, visual outcome, such as a developed and printed photograph. A digitised version of the same photograph, for instance, is easily recognisable, but it is a product of drastically different technological conditions, governed by computational processes in lieu of the mechanical, optical and chemical processes employed in analog photography. In this sense, algorithmicallyproduced images expand upon existing forms of automated production, placing emphasis on the execution of formal procedures in addition to their optical properties. An algorithm, it is worth noting, is a "process or set of rules to be followed in calculations or other problem-solving operations, especially by a computer" ("Algorithm"). The operative image takes a fairly broad interpretation of this definition, which is useful as we expand our approach to image-production processes that at first glance may not appear to be algorithmic in the more familiar, contemporary sense of complex computational processes, but instead embody procedural processes toward the execution of an image.

The problem that automating processes of image production posed to existing notions of aesthetic value in images was famously wrestled with by Walter Benjamin in his essay "The Work of Art in the Age of Mechanical Reproduction." Mechanising the production of images enabled multiples to be produced quickly via technologies such as the printing press and the photographic process, and also enabled the mass-dissemination of images. The facilitation of the serial reproduction of images undermined the aura of the original artwork, which had been a mainstay of artistic valuation up to that point. Artists including Andy Warhol and later the art and design group Superflex have played upon the aspect of seriality, making multiples of images to undermine the notion of the copy as inferior. In other developments in the mechanisation of the image, precursors to film, or "pre-cinema", saw the creation of a variety of optical gadgets and machines which activated images in various ways, from illumination to animation. Cinema set the image in motion through variations of multiple images, simulating movement: the "movement-image" and the "time-image" (Deleuze). Digital images allowed the electronic coding, display and circulation of images, and this was pushed even further with the use of the internet. Networked images, as Alexander Galloway points out (94), may be displayed on innumerable computers simultaneously, adding to the mass-transmissibility and intangibility of the image. Generative art went on to consider the artistic potential of employing autonomous systems to produce images.

In addition to the technical modes of the automation of image production previously described, formalising processes of artistic creation in terms of algorithmic behaviour also explored the dynamics of human-machine relations. Rather than a fixed outcome from image-production processes, the operative image may be performed or it may be transcoded as sets of instructions. Several artists who were early-adopters of using computers in their work also experimented with taking on a performative role in the production of images, placing the emphasis on process. Vera Molnár, for example, is known for her "machine imaginaire," which implemented instructions for the production of visual outcomes, the artist herself taking on the conceptual role of a computer, one which (or whom) computes, performing tasks based on a set of predefined rules ("Image Machine" 141-142). Taking on this kind of instrumental role has been a recurring theme in several avant-garde movements in the $20^{\text {th }}$ century, importantly the Surrealists' engagement with the concept of automatism. They approached the mechanisation of art by advocating that artists relinquish conscious control over the artistic process so as to arrive at art produced 
by the subconscious mind. Automatic writing, drawing, and painting led artists to develop methodologies seeking to elude their own consciousness, often by employing highly systematised, rule-based techniques to surrender creative control by engaging with serendipity and randomness. In many instances, the artist expressly sought to hand over agency, intentionality, or control to a process, machine or system. One of the most famous and influential methods to materialise from this kind of aleatory approaches (Carvalhais) is the "cut-up method" which Brion Gysin is credited for,[2] a process in which a linear text would be dismembered at random and rearranged by the artist, influencing the creation of a new work from the rearrangement of an existing one. Conceptual artists such as Sol LeWitt, Yoko Ono, John Cage and Lawrence Weiner have similarly employed sets of rules in the creation of their works. Thinking of the process as a form of machinic or programmed image-production grasps the operative property of performing algorithmic processes. Implementing rule-based systems such as in LeWitt's instruction-based drawings, the artist gives directions for the construction of the work, which may be executed with some degree of variation.

Returning to the importance of text to the origins of the operative image, as was apparent in Barthes, several thinkers have explored how relations between images and texts contribute to their algorithmic qualities. In his enquiries into what he terms "imagetexts," W. J. T. Mitchell demonstrates the various modes of interrelation between images and texts. Rather than merely referring to reality, as the image functions in representational terms, imagetexts consider the interrelation between objects, texts, and images, and their potential to be enacted through various forms of mediation. Similarly, Vilém Flusser explored textual aspects of images as being critical to their technical character. Flusser describes "technical images" as those images which have supplanted texts, not only those which owe their existence to technical apparatus in a direct sense (7). In addition to their technical mode of production, the codification and instrumentation of images also adds to their technical and textual character. Ingrid Hoelzl and Rémi Marie make a correlation between the algorithmic nature of digital images and the history of cartography (99), which shifted from thinking of maps as representations of the world in pictures to such a representation instead taking the form of a data set. Cataloguing the systematised coordinates marking the locations of geographic features and their relative spatial relations as an index of mathematical information made it possible for Ptolemy's atlas of maps, Geographia, to be saved, transmitted and later reconstructed. The process of transcribing a visual representation, in this case, a map, from image to numerical data and back into an image allows us to see a close parallel in other image processes, namely, the digital. Considering this index of coordinates as a set of instructions or sourcecode for the reconstruction of the maps, though simplified and analogue, is much like the instructional aspect of digital images. In a similar fashion, the canon of proportions outlined by Vitruvius in his De architectura describes representation of the human body geometrically, as if to function as instructions for its reconstruction: "The length of the foot is one sixth of the height of the body; of the forearm, one fourth; and the breadth of the breast is also one fourth." (Vitruvius)

In this and the previous pre-digital example, mathematical formulae and the systematic cataloguing of the internal relationships within images enabled them to be transcribed, stored, transmitted and reiterated. Not only did this enable a great deal of 
new possibilities, for instance making iterations of an image, it also allowed a degree of faithfulness to be maintained within the copies.

\section{Discussion}

To speak of automation begs the question of autonomy. In this case, one must ask what the operative image means not only for the production of images by machines, but also with respect to the sharing a viewpoint with the inanimate (Virilio 59). In what has been referred to as the "algorithmic turn" (Ulricchio, Hoelzl and Marie), what is visibly apparent on the surface of an image is only one aspect of the processes at work in algorithmic media. The information content of a digital image, for example, is largely unvisualised, acting as the code for its enactment, often through screens, and the image takes on a more dynamic quality than a static entity. The visible surface of the digital image is subjugated to the invisible "subface" (Nake) behind it, for instance, in contexts involving the automated processing of spatial data, where it may or may not be necessary to visualise the end result, in looking at the metadata attached to an image, or in comparing two seemingly identical images which were produced using different algorithms. The algorithmic processes responsible for what is eventually visualised as a digital image may vary greatly, whether or not those differences are visibly discernible to the human eye. But especially notable here is that when using algorithmic approaches such as machine learning to generate images based on vast amounts of training data, entire databases of images are subsumed by the resulting images. In a sense, such images are similar to composites merging the numerous images which an algorithm was trained on, yet much of that visual data, as well as the procedure which governed the end result is obscured.

In situations such as when a camera or other instrument serves as a stand-in, taking the place of the eye, technology enables humans to see in ways impossible to the naked eye, but also steals away other aspects one expects in an image. What is apparent to human viewers observing input intended for machines is that operative images function based on different parameters and are not necessarily burdened with any need to communicate with human vision. This quality makes them decidedly different from previous conceptions of images. Not only has the machine been thoroughly accepted as a surrogate for the eye, but in some cases, such as the instances covered by Farocki's Eye/Machine, the eye may be dispensed of entirely. A consequence of distancing visual perception from the eye through apparatus is articulated through operative images as an ever more blurry boundary between human and nonhuman agency. Not principally of the human, by the human, nor for the human (Zylinska 5), nonhuman forms of images fulfil Virilio's prediction regarding the automation of perception through cameras controlled by computers (59). The result of this automation of vision, a splitting of the viewpoint with the inanimate (Virilio 59), entails that these images are far from being self-evident. Looking alone is not sufficient to thoroughly grasp what is at stake in the output of algorithmic modes of image production. As a consequence of the operative image, the range of what may be considered to be an image is expanded to include non-optical, algorithmic processes, prioritising process over the image's visible qualities.

The operative image is significant, not only because it alters what, ontologically speaking, may be defined as an image, but it also extends the role of image production beyond the human to autonomous (or 
semi-autonomous) enactment by machine. Automating aspects of the creative process calls into question some of the entrenched value systems surrounding images, namely authorship (Ward and Cox). The aura of authorship remains an enduring issue at stake in the production of images by machines, as evidenced by the current hype around works of dubious artistic quality (Obvious) which make claims to the autonomous creativity of machines. Concerns around authorship are never far behind discussion of automating the production of images by machine, the potential of autonomous artistic creation by machines threatening the "death of the author" (Barthes). Curiously, Harold Cohen alternated between signing images produced using the artificial intelligence software he created with his own signature (Amsterdam Suite $A)$ and that of AARON (20:28). This lends the artworks a sense that Cohen may have either felt conflicted as to his role in creating the artwork, and that there may have been a feeling of competition for authorship. In a general sense, the images produced using machine learning, too, carry with them a spectre which has haunted technologicallyengaged images throughout the past century, what Andreas Broeckmann calls the myth of the machine as artist. The persistent curiosity surrounding the creation of autonomous agents which in turn create art relies upon the tradition of conceptually separating science and the humanities. While machine learning enables the automation of certain tasks, it also lends itself to a mystification of the process of image production. Image production by intelligent machines offers new technical and conceptual possibilities, it also brings to light certain existing issues which have persisted throughout the past century, including automation, seriality, transcodability and human-machine relations.

\section{Conclusion}

Much as historical reckonings with technological modes of production such as the advent of the printing press, photography or cinema led to reevaluations of the image, the current gravitation toward algorithmic processes has led to new understandings of the defining attributes of images. Rather than a fundamentally new phenomenon, current methodologies instead expand upon the automation of image production which has been in progress for decades and even centuries. Reformulating the image as an operation which is performed as opposed to the fixed outcome of the creative process, the operative image offers an entryway to rethinking the context surrounding the automation of image processes which current media build upon. Developing the concept of the operative image through an overview of historically-significant theories and examples, this research aims to develop an understanding of how the concept of the operative image contributes to a reevaluation of the image in light of new modalities introduced by algorithmic media. 


\section{Notes}

[1] Farocki uses the two words, operative and operational, for the most part interchangeably in his video work and writing. Other thinkers, including Trevor Paglen and Jussi Parikka have gravitated toward operational, but the author chooses to use the former, operative, as it indicates the sense of agency expressed by machines in the performance of operational images.

[2] William S. Burroughs is also known for popularising the practice of the cut-up method.

\section{Works cited}

"Algorithm." Oxford English, Oxford University Press, 2019. https:// en.oxforddictionaries.com/definition/algorithm. Accessed 14 May 2019.

Barthes, Roland. Mythologies. Editions du Seuil, 1957.

-. "The Death of the Author." Image-MusicText, Fontana Press, 1977, pp. 142-48.

Benjamin, Walter. "The Work of Art in the Age of Its Technological Reproducibility: Second Version." The Work of Art in the Age of Its Technological Reproducibility and Other Writings on Media, edited by Michael W. Jennings et al., Harvard/Belknap Press, 2008, pp. 19-55.

Broeckmann, Andreas. "Image Machine." Machine Art in the Twentieth Century, MIT Press, 2016, pp. 123-64.
—. "The Machine as Artist as Myth." Arts, vol. 8, no. 1, February 2019, p. 25.

Burroughs, William S. "The Cut-Up Method of Brion Gysin." The New Media Reader, edited by Noah Wardrip-Fruin and Nick Montfort. MIT Press, 2003.

Carvalhais, Miguel. Artificial Aesthetics: Creative Practices in Computational Art and Design. U. Porto Edições, 2016, pp. 145-178.

Cohen, Harold. 20:28. 1985.

—. Amsterdam Suite A. 1977.

Deleuze, Gilles. Cinema 1: The MovementImage, translated by Hugh Tomlinson and Barbara Habberjam. University of Minnesota Press, 1986.

-. Cinema 2: The Time-Image, translated by Hugh Tomlinson and Robert Galeta. University of Minnesota Press, 1989.

Farocki, Harun. "Phantom Images." PUBLIC, edited by Saara Liinamaa et al., vol. 29, 2004, pp. 12-22.

Flusser, Vilém. Into the Universe of Technical Images, translated by Nancy Ann Roth. University of Minnesota Press, 2011.

Galloway, Alexander. "Are Some Things Unrepresentable?" Theory, Culture \& Society, vol. 28, no. 7-8, December 2011, pp. 85-102.

González Valerio, María Antonia. "Politics of Machines or the Anthropogenenesis as a Confrontation with a Certain Kind of Nature." Open Hardware/Open Machines, Aalborg University, Copenhagen. 14 May 2018. 
Harman, Graham. "Aesthetics Is the Root of All Philosophy." Object Oriented Ontology: A New Theory of Everything. Pelican Books, 2017, pp. 61-102.

Hoelzl, Ingrid. "Postimage." Posthuman Glossary, edited by Rosi Braidotti and Maria Hlavajova, Bloomsbury Academic, 2018.

Hoelzl, Ingrid, and Rémi Marie. Softimage:

Towards a New Theory of the Digital Image. Intellect, 2015.

Kittler, Friedrich. "The Finiteness of Algorithms." transmediale. https://transmediale.de/content/the-finiteness-of-algorithms.

Mitchell, W. J. T. Iconology. University of Chicago Press, 1986.

Nake, Frieder. "Surface, Interface, Subface: Three Cases of Interaction and One Concept." Paradoxes of Interactivity: Perspectives for Media Theory, HumanComputer Interaction, and Artistic Investigations, edited by Uwe Seifert et al., Transaction Publishers, 2008, pp. 93-109.

Obvious. Edmond De Belamy. 2018.

Parisi, Luciana. 'Instrumental Reason, Algorithmic Capitalism and the Incomputable'. Alleys of Your Mind: Augmented Intelligence and Its Traumas, edited by Matteo Pasquinelli, Meson Press, 2015, pp. 125-137.

Ulricchio, William. "The Algorithmic Turn: Photosynth, Augmented Reality and the Changing Implications of the Image." Visual Studies, vol. 26, no. 1 (Mar 2011): 25-35.

Virilio, Paul. "The Vision Machine." The Vision Machine, British Film Institute/Indiana University Press, 1994, pp. 59-77.
Vitruvius Pollio, Marcus. De Architectura, 15 A.D, 3.1.2-3. https://en.wikipedia.org/wiki/ Vitruvian_Man.

Ward, Adrian, and Geoff Cox. "How I Drew One of My Pictures: or, The Authorship of Generative Art." International Conference on Generative Art 1999, Milan 1999. http:// www.generativeart.com/on/cic/99/0399.htm.

Zylinska, Joanna. Nonhuman Photography. MIT Press, 2017. 